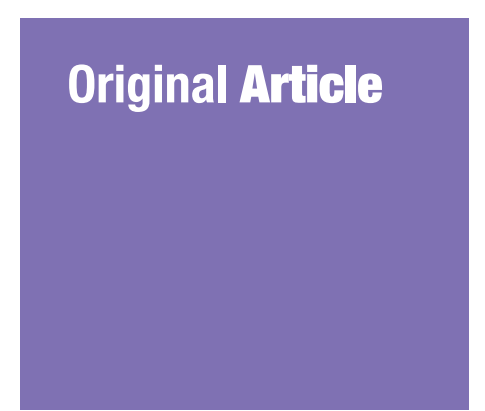

Submitted: 8 Aug 2016 Accepted: 26 Apr 2017 Online: 30 Jun 2017

\section{Development and Validation of a Coping Scale for Caregivers in Malaysia}

\author{
Norhayati IBrahim ${ }^{1}$, Hui Chien ONG ${ }^{1}$, Suzaily WAHAB ${ }^{2}$
}

Health Psychology Programme, School of Healthcare Sciences, Faculty of Health Sciences, Universiti Kebangsaan Malaysia, Jalan Raja Muda A. Aziz, 50300 Kuala Lumpur, Malaysia

$2 \quad$ Psychiatry Department, Faculty of Medicine, Universiti Kebangsaan Malaysia Medical Centre, Jalan Yaacob Latif, Bandar Tun Razak, 56000 Cheras, Kuala Lumpur, Malaysia

To cite this article: Ibrahim N, Ong HC, Wahab S. Development and validation of a coping scale for caregivers in Malaysia. Malays J Med Sci. 2017;24(3):83-91. https://doi.org/10.21315/mjms2017.24.3.10

To link to this article: https://doi.org/10.21315/mjms2017.24.3.10

\begin{abstract}
Introduction: Caregivers often experience stressful situations while in the midst of the caregiving process. Thus, various methods of coping have been widely applied and studied in previous researches. The aim of this study was to develop a novel questionnaire to assess the coping strategies employed by those who provide care to patients, and to further validate it among caregivers of schizophrenia patients in Malaysia.

Methods: This study, which involved the caregivers of schizophrenia patients from a hospital in Kuala Lumpur, Malaysia, was comprised of three parts, namely in-depth interviews, a pilot study, and the validation of the developed questionnaire, known as Caregiver Cope (CgCope $\left.{ }^{\mathrm{TM}}\right)$.

Results: Part A originally consisted of eight themes, and it was later modified to seven themes with four items each after discussions with some experts. Part B initially had 28 items derived from the seven themes in Part A, which were then reduced to six components after a factor analysis. Part $C$ of the questionnaire consisted of 19 items, with six components (Distraction, Caring for patient, Venting, Religion, Recreation, and Social support) having a moderate to high reliability ranging from a Cronbach's alpha coefficient of 0.54 to 0.82 . A factor analysis showed that the six factors of coping accounted for $62.36 \%$ of the total variance.

Conclusion: The $\mathrm{CgCOPE}^{\mathrm{TM}}$ questionnaire is suitable for use among caregivers of schizophrenia patients. There is a need to further validate the instrument among caregivers of other patient populations.
\end{abstract}

Keywords: coping skills, questionnaires, family caregivers, schizophrenia, Malaysia

\section{Introduction}

The history of coping has been documented since the early approaches to stress in the $14^{\text {th }}$ century $(1,2)$. In the 1960 s, coping was described as a process, and gained importance as 'a person's on-going effort to manage specific demands appraised as taxing or overwhelming' (2-4) along with studies on the development of psychological stress in people. This concept was widely researched with various definitions and approaches in later studies. One of the commonly used theories was the stress and coping theory of Folkman et al. (5).

Coping is a wide concept with no standard measurements, and past studies have summarised it into different approaches. In previous studies, coping was categorised into three main types of approaches. Firstly, coping can be divided into problem-focused or emotion-focused coping. According to Folkman and Lazarus (6), problem-focused strategies are efforts at doing something active to alleviate a stressful situation, while emotion-focused strategies are the efforts of an individual to 
control the emotions brought about by stressful events. Both types of strategies are commonly used in encountering stressful situations. Next, coping is also divided into active coping and avoidance coping. Past researchers have defined active coping as the way individuals think or react in order to change a stressful situation, whereas in avoidance coping, the individuals involve themselves in activities or adopt mental states that keep them away from the stressful situation or help them not to face the situation. Holahan and Moos (7) found that active coping is more effective in handling stressful situations compared to avoidance coping, which is also called the risk factor. In addition, the coping approach has also been divided into a style or process (2), while others have categorised it as adaptive and maladaptive coping.

To date, a few coping questionnaires are available to assess the coping strategies used by various populations-patients, children, teenagers, or targeted audiences. Most questionnaires cover various coping strategies, for example, the COPE inventory or the abbreviated version. The Brief COPE inventory by Carver et al. (8) has 14 subscales ranging from problem-focused coping strategies to emotionfocused coping strategies that are suitable for use by anyone wanting to assess the coping strategies used during stressful events.

Not many coping questionnaires have been developed based on specific diseases or a specific community. However, Magliano et al. (9) developed the Family Coping Questionnaire (FCQ) to explore the coping strategies adopted by relatives of schizophrenia patients in Italy. The subscales for the FCQ were information, positive communication, social interests, coercion, avoidance, resignation, and patient's social involvement. The development of the FCQ was based on the Western social context, and, hence, some of the items may not be valid in certain cultures or countries, especially in Asia. A previous study found that caregivers of schizophrenia patients in Malaysia often use religion (10) as their coping strategy. Moreover, there are also some good coping questionnaires available for general populations. However, these populations might use different coping strategies during stress, while those questionnaires do not contain components that are targeted on caregiving such as caring for patients, which are included in this newly-developed coping questionnaire.

Due to the limited number of coping questionnaires available, especially for caregivers, and the unavailability of a coping questionnaire for caregivers in the context of Malaysia, this study was aimed at developing a new questionnaire designed specifically to assess the coping skills used by caregivers during stressful times in the caregiving process based on the Malaysian context. An assessment of the coping behaviour among caregivers will enable health professionals to design better interventions and programmes on behavioural changes for caregivers to enhance the caregiving process. This paper describes the process and phases involved in the development and validation of a new questionnaire, known as the Caregiver Cope $\left(\mathrm{CgCope}^{\mathrm{TM}}\right)$ questionnaire, which explores the coping strategies used by caregivers of schizophrenia patients in Malaysia. Schizophrenia is a chronic mental disorder with a wide range of symptoms, and it consists of complex influences on the thoughts, perceptions, social behaviour and overall functions of patients, especially in serious cases (11). Due to the complexity of the illness, caring for schizophrenia patients may involve high levels of stress, and often requires patience, knowledge and skills. Hence, the aim of this study was to further validate the questionnaire among those who provide care to this population of patients. The data collection process was divided into three phases, and the factor analysis showed the formation of various subscales, which will be discussed next. This study hypothesised that the questionnaire was built with various components based on high reliability and validity.

\section{Materials and Methods}

\section{Participants and Procedure}

The duration for the data collection was approximately four months. The research protocol was approved by the Medical Centre Research Ethics Committee of Universiti Kebangsaan Malaysia (UKM 1.5.3.5/244/NN057-2015). The procedure was divided into three parts. In part A, in-depth interviews were conducted among the caregivers; in part $\mathrm{B}$, a pilot study of the $\mathrm{CgCope}^{\mathrm{TM}}$ questionnaire was carried out; and in part $\mathrm{C}$, the $\mathrm{CgCope}^{\mathrm{TM}}$ questionnaire was used on the caregivers of schizophrenia patients. A sample of 20 caregivers participated in part A, 71 caregivers in part B, and 200 caregivers in part $\mathrm{C}$. The recruiting methods differed for each part. In part A, the researchers stopped recruiting new samples after 
20 caregivers, as the outcomes of the interviews had been saturated (12); for part B, samples were collected within a period of one month; and for part $\mathrm{C}$, the participants were recruited based on the availability of caregivers at the sample site within a period of four months. Comrey and Lee (13) regarded 200 participants to be a fair sample size, while Guadagnoli and Velicer (14) believed that if several high loading (> o.80) variables are present, then a big sample size is not required. The $\mathrm{CgCope}^{\mathrm{TM}}$ questionnaire was part of a larger study. The estimated sample size was 194, while a total of 200 samples were collected in this study. The participants were recruited using the purposive sampling method. The inclusion criteria comprised caregivers of schizophrenia patients aged more than 18 years old, who accompanied their schizophrenia relatives during clinic follow-up, were involved with the full-time care of their schizophrenia relatives, had no psychiatric illness, and were able to read and understand Bahasa Malaysia. For all the parts $\mathrm{A}$ to $\mathrm{C}$, the researchers obtained the list of names of the caregivers using the patients' appointment list at the Psychiatry Clinic of a tertiary hospital in Kuala Lumpur. The written informed consent of the caregivers was obtained prior to their enrolment in the study.

During the interviews in part $\mathrm{A}$, the caregivers were asked about their stress and the coping methods they used to overcome the situation. Four main open-ended questions were asked during the interviews: 'Do you feel stressed when you take care of your relative (the patient)?'; 'When is the most stressful time during the caring process?'; 'What do you do to overcome the stress?' and 'What are the three things you find most helpful in overcoming your stress?' The researchers continued probing based on the answers given by the caregivers. The researchers did an extensive literature review on the factors related to the coping strategies among caregivers and referred to the stress-coping theory as the basis for asking the interview questions. Hence, the questions were designed to screen the caregivers' stress and their usage of any coping strategies before further exploring the coping strategies employed by them.

Part $\mathrm{B}$ was the development of $\mathrm{CgCope}^{\mathrm{TM}}$ for the caregivers and the pilot study. The questionnaire items were derived from the answers to part A, and the details concerning the construction of the items are explained in the next section. This research also used the Brief COPE questionnaire to test the coping methods used by the caregivers to overcome stress as well as to compare the validity with the $\mathrm{CgCope}^{\mathrm{TM}}$. The necessary modifications were made based on the results. The questionnaire was developed in the Malay language.

Lastly, part $\mathrm{C}$ consisted of the final coping questionnaire, which was tested on 200 caregivers of schizophrenia patients. The recruitment process also included the demographic profiles of the caregivers, followed by the self-reported measures and the face-toface interviews by the researcher.

\section{Data Analysis}

The data in Part A was transcribed manually using Microsoft Word tables. The Statistical Package for Social Sciences (SPSS) version 22.0 software was used to analyse the data for Part $\mathrm{B}$ and Part C in this study. Cronbach's alpha coefficient was used to measure the internal consistency of the items. A factor analysis with a varimax rotation was used to investigate the construct validity of the $\mathrm{CgCope}^{\mathrm{TM}}$ items. Lastly, the concurrent validity of the $\mathrm{CgCope}^{\mathrm{TM}}$ components and the Brief COPE components was analysed by Pearson's correlation.

\section{Results}

\section{Part A}

The coping themes were extracted manually from the outcome of the interviews and were grouped together. Eight themes were extracted from the transcriptions (Distraction, Avoidance, Caring for patient, Emotional expression, Religion, Recreation, Emotional support, and Instrumental support). The themes were later modified into seven themes (Distraction, Caring for patient, Emotional expression, Religion, Recreation, Emotional support, and Instrumental support) after discussion with experts from the research team who had backgrounds in psychology and psychiatry. 'Avoidance' was combined with 'Distraction' due to the similarity of the descriptions and because it was not appropriate to consider them as separate themes. In addition, 'Emotional expression' was changed to 'Venting' as it was more suitable for explaining the negative emotions that were used, as described by the caregivers, during the coping process. The researchers developed four items for each theme, as shown in Table 1. 
Table 1. Reliability and item reduction summary

\begin{tabular}{lccccc}
\multicolumn{1}{c}{ Factor } & $\begin{array}{c}\text { No. of items } \\
\text { Initial }\end{array}$ & Final & $\begin{array}{c}\text { Cronbach's alpha } \\
\text { before }\end{array}$ & $\begin{array}{c}\text { Cronbach's alpha } \\
\text { after }\end{array}$ & $\begin{array}{c}\text { Minimum } \\
\text { CITC }\end{array}$ \\
Distraction & 4 & 3 & .472 & .636 & .350 \\
Caring & 4 & 4 & .650 & .650 & .317 \\
Venting & 4 & 2 & .423 & .625 & .458 \\
Religion & 4 & 4 & .812 & .812 & .518 \\
Recreation & 4 & 3 & .514 & .517 & .322 \\
Emotional support & 4 & 2 & .597 & .747 & .638 \\
Instrumental support & 4 & 2 & .433 & .594 \\
\hline
\end{tabular}

\section{Part B}

The CgCope ${ }^{\mathrm{TM}}$ questionnaire was comprised of 28 items based on the seven themes extracted from Part A. A reliability analysis of the items showed that some items $(6,12,14,15,17,20$, 24, and 28) had inter-item correlations and a minimum corrected item-total correlation (CITC) of less than 0.3, making the Cronbach's alpha coefficient value lower. When the researchers removed the eight items, the Cronbach's alpha value increased, as shown in Table 1. Next, the researchers ran a dimension reduction analysis to ensure that the remaining items were maintained in the original components. Principal component and varimax rotation analyses were used on the 20 items based on the data from 71 caregivers. The Kaiser-Meyer Olkin (KMO) measure of sampling adequacy showed that the samples could be factorised $(0.56>0.3)$.

The factor loading for each item is shown in Table 2. All the items obtained a loading value of more than o.6. However, item 16 (Saya memberitahunya bahawa keadaan akan menjadi lebih baik.), which was originally located in the 'Caring for patient' theme, developed its own component with a high loading value; therefore, the item was removed to ensure that a new component was not developed based on just one item. The initial 28 items created at the beginning of the study were reduced to 19 items. The researchers also combined 'Emotional support' and 'Instrumental support' in the same component, which was known as 'Social support'.

Next, a Pearson's correlation analysis was run to measure the concurrent validity of the $\mathrm{CgCope}^{\mathrm{TM}}$ components and Brief COPE components. The results showed that 'Distraction' had the highest number of correlations with 'Behavioural disengagement' ( $r=0.332, P=0.000)$ and 'Self-distraction' ( $r=0.302, P=0.000)$. 'Caring for patient' correlated the highest with 'Acceptance' ( $r=0.332, P=0.000$ ) and 'Positive reframing' $(r=0.313, P=0.000)$. 'Venting' correlated the highest with 'Venting' in Brief COPE $(r=0.374$, $P=0.000)$. 'Religion' correlated highly with 'Religion' in Brief COPE ( $r=0.715, P=0.000)$. 'Recreation' correlated highly with 'Humour' ( $r=0.382, P=0.000$ ), and, lastly, 'Social support' correlated highly with 'Use of emotional support' $(r=0.627, P=0.000)$ and 'Use of instrumental support' $(r=0.705, P=0.000)$ (refer to Table 3).

\section{Part C}

The researchers ran another factor analysis on the data of 200 caregivers and found that the KMO value was high $(0.71>0.7)$. All the items remained with their components and had moderate to high internal consistency reliability scores (> 0.5). It was found that 'Religion' had the highest reliability ( $\alpha=0.817$ ), followed by 'Social support' ( $\alpha=0.761)$ and 'Caring for patient' ( $\alpha=686$ ). 'Distraction' had a reliability of $\alpha=0.539$, 'Venting', a reliability of $\alpha=0.561$, and 'Recreation', a reliability of $\alpha=0.561$. A factor analysis using varimax rotation showed that six factors of coping accounted for $62.36 \%$ of the total variance. The highest scoring factor was 'Religion' (14.18\% of variance), followed by 'Social support' (12.96\% of variance), 'Caring for patient' (10.31\% of variance), 'Recreation' ( $8.55 \%$ of variance), 'Distraction' (8.5\% of variance), and 'Venting' ( $7.87 \%$ of variance). 
Original Article | Development of coping scale for caregivers

Table 2. Factor loading for items according to rotated component matrix

\begin{tabular}{|c|c|c|c|}
\hline Component & Item No. & Item & Factor Loading \\
\hline \multirow[t]{3}{*}{ Distraction } & 1 & Saya menjauhkan diri saya darinya... & .852 \\
\hline & 8 & Saya hanya membiarkannya... & .704 \\
\hline & 22 & Saya keluar dari rumah seketika... & .605 \\
\hline \multirow[t]{3}{*}{ Caring } & 2 & Saya memberi lebih perhatian... & .705 \\
\hline & 9 & Saya bercakap secara baik... & .745 \\
\hline & 23 & Saya menjaganya dengan... & .669 \\
\hline \multirow[t]{2}{*}{ Venting } & 3 & Saya bercakap dengan nada... & .812 \\
\hline & 10 & Saya mengeluarkan kata-kata... & .843 \\
\hline \multirow[t]{4}{*}{ Religion } & 4 & Saya berdoa... & .656 \\
\hline & 11 & Saya ke tempat... & .853 \\
\hline & 18 & Saya membaca buku-buku... & .792 \\
\hline & 25 & Saya menghadiri majlis-majlis... & .872 \\
\hline \multirow[t]{3}{*}{ Recreation } & 5 & Saya bersenam... & .756 \\
\hline & 19 & Saya melakukan perkara-perkara lain... & .637 \\
\hline & 26 & Saya keluar berjalan-jalan... & .674 \\
\hline \multirow[t]{4}{*}{ Social support } & 7 & Saya meminta bantuan... & .730 \\
\hline & 13 & Saya berbincang masalah... & .801 \\
\hline & 21 & Saya mendapatkan bantuan penjagaan... & .778 \\
\hline & 27 & Saya berkongsi masalah... & .774 \\
\hline Additional component & 16 & Saya memberitahunya bahawa keadaan... & .806 \\
\hline
\end{tabular}




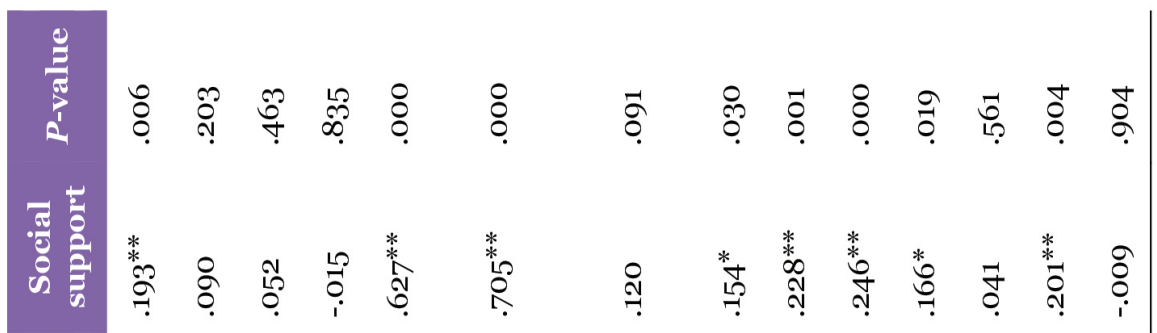

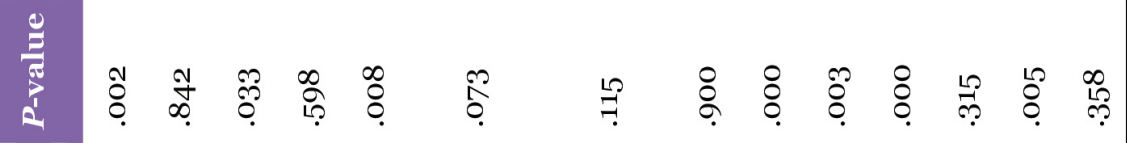

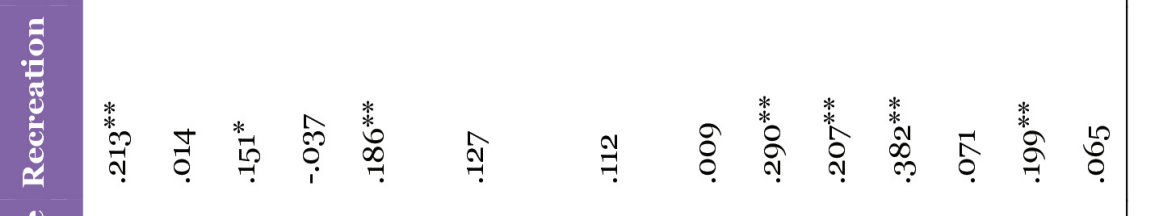

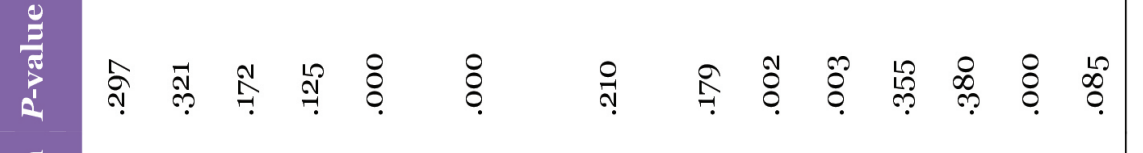

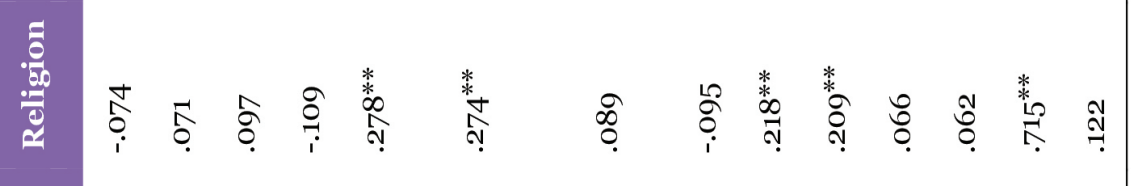

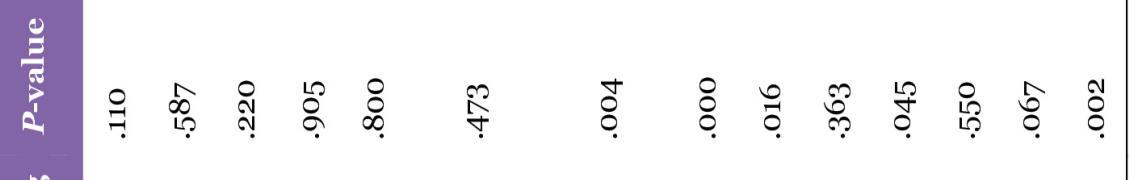
四

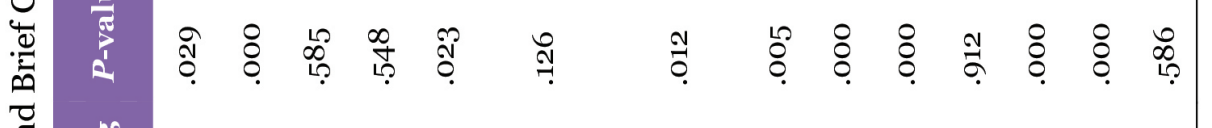

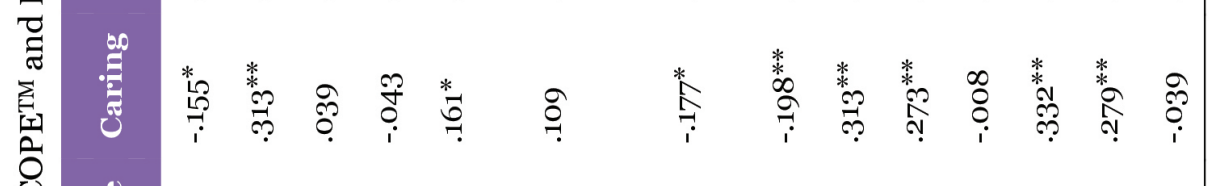

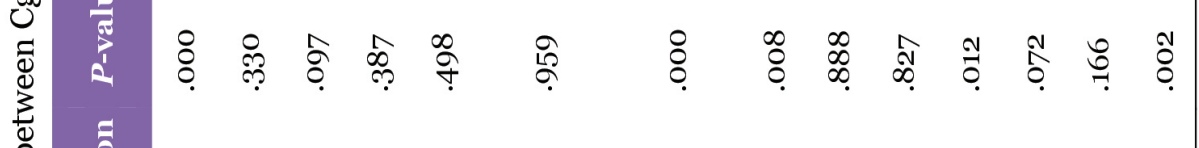

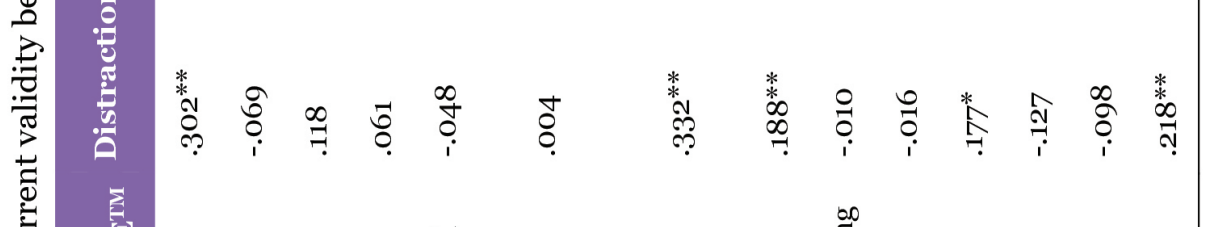

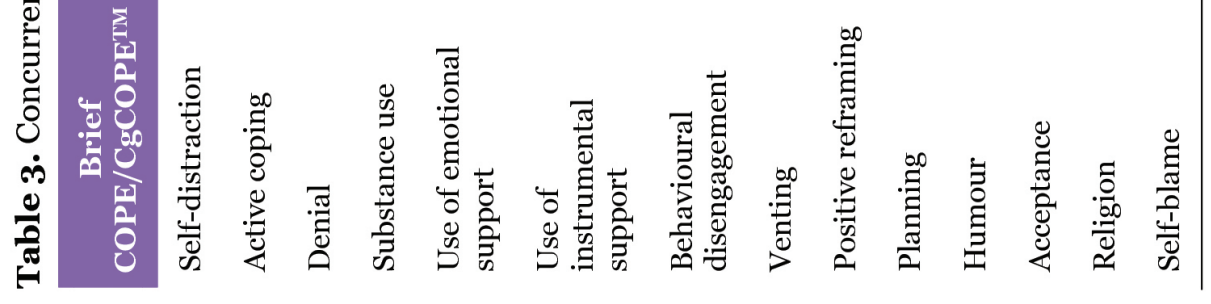




\section{Discussion}

In this paper, the researchers developed a new questionnaire to assess the coping strategies used by caregivers in Malaysia when they feel stressed while taking care of their patients. The final $\mathrm{CgCope}^{\mathrm{TM}}$ questionnaire consisted of six components with 19 items, which had a Cronbach's alpha coefficient ranging from 0.54 to 0.82 as a measurement of the internal consistency reliability. All the components were formed from the results of the factor analysis and represented all the themes collected from the indepth interviews (Part A).

In Part $\mathrm{C}$, the results of the factor analysis that was performed on the questionnaire were consistent with the components for the previous coping strategies (Part A). First of all, 'Distraction' was categorised as an adaptive trait (15), and was sometimes considered as an accommodative strategy (16), where a person shifts his/her attention from the real goal to accept the sad facts and to control unpleasant situations. However, it depends on the situation, and this strategy has been found to be more common and efficient in unchanged situations, and is widely used among caregivers above 70 years old for greater control (17). The caregivers indicated that they often use this strategy, as shown by their answers: 'I move myself away from my relative', and 'I go out of the house for a while'. The research also showed that it is a passive strategy to solve their problems (18).

Next, the 'Caring for patient' component was a new component created in this study. However, it is considered to be similar to 'Positive communication' in the FCQ, which is a problem-focused strategy. A previous research found that 'Positive communication' is one of the commonly-used strategies among main and side caregivers (19). This 'Caring for patient' strategy involves giving more attention and speaking in good ways to the patients during stressful times, unlike other strategies which involve actions or activities that focus more on the caregivers themselves.

Past researches categorised the 'Venting' strategy as maladaptive coping $(8,20)$. It can also be in the form of emotional expressions, such as crying or getting angry, and is often shown by family members and friends. It is considered to be a healthy strategy if used in moderation (21). However, if an individual uses this strategy too often and ruminates on the problems, Thompson et al. (22) found that it can also be correlated with depression.
The 'Religion' component had the highest Cronbach's alpha value compared to the other components, similar to some earlier researches which showed a high internal consistency (23, 24). The 'Religion' coping strategy functions as a source of emotional support (8), and is often used (25-27) especially when someone experiences stress due to various reasons (24). Fortune et al. (28) reported that lower distress was correlated with the 'Religion' coping strategy used by caregivers of schizophrenia patients. Although it is always used by caregivers, some researchers have stated that this coping strategy is more appropriately labelled as maladaptive coping (15).

Next, although the 'Recreation' strategy is rarely used in any other coping scale, it is similar to the 'Physical recreation' strategy in the Adolescent Coping Scale - Second Edition (ACS2), which is categorised as productive coping. In this study, 'Recreation' included any physical activity-hobbies or exercises-that caregivers apply during stress to make them feel relaxed.

The last coping strategy, 'Social support', can function as a problem-focused or emotionfocused strategy (27), and caregivers may use this coping strategy for both functions based on the situation. Gerson et al. (25) discovered that the family members of psychotic patients use this strategy moderately, and it has been found to be related to lower distress (28).

Even though the $\mathrm{CgCope}^{\mathrm{TM}}$ is a reliable and valid instrument for measuring the coping strategies among caregivers of schizophrenia patients, there are several limitations to the questionnaire that should be acknowledged. This study used a sample of caregivers from just one hospital and covered only one caregiver population in Malaysia, so the results of this study might not fully represent the population of caregivers in Malaysia. Thus, this study should be expanded to caregivers of various diseases in different hospitals in the states in Malaysia to confirm the reliability and validity of this instrument. However, these results may be considered as a first step towards the introduction of the Malay version of the $\mathrm{CgCope}^{\mathrm{TM}}$, while the psychometric properties can be further established through additional research.

\section{Conclusion}

The short 19-item CgCope ${ }^{\mathrm{TM}}$ underwent several analyses to confirm its validity, and it 
was proven to be trustworthy and reliable. The findings from the developed questionnaire were satisfactory, thereby proving its suitability for further use in future research, especially among the Malaysian population. Its ability to identify the coping strategies used by caregivers may assist health professionals in providing tactful psycho-education and interventions to further enhance the process of caregiving and efficiently reduce stress in the caregivers.

\section{Acknowledgments}

This study was supported by the Fundamental Research Grant Scheme (FRGS) [FRGS/1/2014/SSo2/UKM/02/2] from the Ministry of Higher Education, Malaysia. The researchers would like to express their gratitude to the caregivers and healthcare workers who were involved in this study.

\section{Authors' Contributions}

Conception and design: NI, HCO

Analysis and interpretation of the data: NI, HCO Drafting of the article: NI, HCO

Critical revision of the article for important intellectual content: NI, HCO, SW

Final approval of the article: NI, HCO, SW

Provision of study materials or patients: NI, SW

Statistical expertise: NI, HCO

Obtaining of funding: NI

Administrative, technical, or logistic support: NI, $\mathrm{HCO}$, SW

Collection and assembly of data: NI, HCO, SW

\section{Fund}

This work was supported by the Fundamental Research Grant Scheme (FRGS) by the Ministry of Higher Education Malaysia [FRGS/1/2014/SSo2/UKM/02/2]. The role of the sponsor was to fund the process of designing the questionnaire, data collection, and preparing the manuscript to approval.

\section{Correspondence}

Hui Chien Ong

Graduate Research Assistant

Master of Health Science (MHsc)

(Universiti Kebangsaan Malaysia)

Biomedical Science Programme,

School of Diagnostic \& Applied Health Sciences,
Faculty of Health Sciences,

Universiti Kebangsaan Malaysia,

Jalan Raja Muda A. Aziz,

50300 Kuala Lumpur, Malaysia.

Tel: +603 26878198 ,

Fax: +603 26878192

E-mail: onghuichien@gmail.com

\section{References}

1. Lumsden D. Is the concept of "stress" of any use, anymore. Contributions to Primary Prevention in Mental Health: Working Papers. Toronto: Canadian Mental Health Association; 1981.

2. Lazarus RS. Coping theory and research: past, present, and future. Psychosomatic Medicine. 1993;55(3):234-247.

3. Lazarus RS. Psychological stress and the coping process. New York: McGraw-Hill; 1966.

4. Lazarus RS, Averill JR, Opton EM. The psychology of coping: Issues of research and assessment. Coping and Adaptation. 1974;249315 .

5. Folkman S, Lazarus RS, Gruen RJ, DeLongis A. Appraisal, coping, health status, and psychological symptoms. J Pers Soc Psychol. 1986;50(3):571.

6. Folkman S, Lazarus RS. An analysis of coping in a middle-aged community sample. $J$ Health Soc Behav. 1980:219-239.

7. Holahan CJ, Moos RH. Personal and contextual determinants of coping strategies. J Pers Soc Psychol. 1987;52(5):946.

8. Carver CS, Scheier MF, Weintraub JK. Assessing coping strategies: a theoretically based approach. J Pers Soc Psychol. 1989;56(2):267.

9. Magliano L, Guarneri M, Marasco C, Tosini P, Morosini P, Maj M. A new questionnaire assessing coping strategies in relatives of patients with schizophrenia: development and factor analysis. Acta Psychiatr Scand. 1996;94(4):224-228.

10. Mohamad MS, Zabidah P, Fauziah I, Sarnon N. Mental health literacy among family caregivers of schizophrenia patients. Asian Social Science. 2012;8(9):74 
Original Article | Development of coping scale for caregivers

11. National Institute of Mental Health. Schizophrenia [Internet]. Bathesda, MD: NIMH; 2015. Retrieved Jan 2, 2016, from https://www. nimh.nih.gov/health/topics/schizophrenia/index. shtml.

12. Francis JJ, Johnston M, Robertson C, Glidewell L, Entwistle V, Eccles MP, et al. What is an adequate sample size? Operationalising data saturation for theory-based interview studies. Psychology and Health. 2010;25(10):1229-1245.

13. Comrey A, Lee H. A first course in factor analysis. Hillsdale, NJ: Erlbaum; 1992.

14. Guadagnoli E, Velicer WF. Relation to sample size to the stability of component patterns. Psychological Bulletin. 1988;103(2):265.

15. Riley III JL, Robinson ME. CSQ: five factors or fiction? Clin J Pain. 1997;13(2):156-162.

16. Walker LS, Smith CA, Garber J, Van Slyke DA. Development and validation of the pain response inventory for children. Psychological Assessment. 1997;9(4):392.

17. Gollwitzer PM, Brandstätter V. Implementation intentions and effective goal pursuit. $J$ Pers Soc Psychol. 1997;73(1):186.

18. Allen AB, Leary MR. Self-Compassion, stress, and coping. Soc Personal Psychol Compass. 2010;4(2):107-118.

19. Magliano L, Fadden G, Fiorillo A, Malangone C, Sorrentino D, Robinson A, et al. Family burden and coping strategies in schizophrenia: are key relatives really different to other relatives? Acta Psychiatr Scand. 1999;99(1):10-15.

20. Carver CS. You want to measure coping but your protocol'too long: Consider the brief cope. Int $J$ Behav Med. 1997;4(1):92-100.
21. University of California [UCLA]. How Do You Cope? [Internet]. Los Angeles: UCLA; 2015. Retrieved Feb 2, 2016, from: https://www.semel. ucla.edu/dual-diagnosis-program/News_and_ Resources/How_Do_You_Cope.

22. Thompson RW, Arnkoff DB, Glass CR. Conceptualizing mindfulness and acceptance as components of psychological resilience to trauma. Trauma, Violence, \& Abuse. 2011;12(4):220-235.

23. onticone M, Ferrante S, Giorgi I, Galandra C, Rocca B, Foti C. The 27-Item coping strategies questionnaire-revised: confirmatory factor analysis, reliability and validity in Italianspeaking subjects with chronic pain. Pain Research and Management. 2014;19(3):153-158.

24. Yusoff N, Low W, Yip C. Reliability and validity of the Brief COPE Scale (English version) among women with breast cancer undergoing treatment of adjuvant chemotherapy: a Malaysian study. Med J Malaysia. 2010;65(1):41-44.

25. Gerson R, Wong C, Davidson L, Malaspina D, McGlashan T, Corcoran C. Self-reported coping strategies in families of patients in early stages of psychotic disorder: an exploratory study. Early Intervention in Psychiatry. 2011;5(1):76-80.

26. Kasi PM, Naqvi HA, Afghan AK, Khawar T, Khan FH, Khan UZ, et al. Coping styles in patients with anxiety and depression. ISRN Psychiatry. 2012.

27. Mukwato K, Mweemba P, Makukula M, Makoleka M. Stress and coping mechanisms among breast cancer patients and family caregivers: A Review of literature. Med J Zambia. 2010;37(1):40-45.

28. Fortune DG, Smith JV, Garvey K. Perceptions of psychosis, coping, appraisals, and psychological distress in the relatives of patients with schizophrenia: An exploration using self-regulation theory. $\mathrm{Br} J$ Clin Psychol. 2005;44(3):319-331. 